\title{
Vivências de policiais de uma DEAM no Sudoeste Goiano
}

\author{
Tatiana Machiavelli Carmo Souza, ${ }^{(\mathbb{D}} \star$ Thaís Ferreira Martins \\ Universidade Federal de Catalão, Catalão, Goiás, GO - Brasil
}

\begin{abstract}
Resumo
A pesquisa investigou as vivências de policiais civis de uma Delegacia Especializada de Atendimento à Mulher (DEAM) em um municipio do sudoeste goiano no atendimento às mulheres em situação de violência doméstica. Partindo da abordagem qualitati$v a$, realizaram-se entrevistas semiestruturadas com quatro policiais, duas mulheres e dois homens. Identificaram-se diversas dificuldades vivenciadas no cotidiano profissional, desde a falta de espaço físico, funcionários e tempo, até a ausência de capacitação para o atendimento às mulheres. Embora tivessem conhecimento sobre a Lei Maria da Penha, as/os participantes reproduziam concepções de gênero machistas e misóginas que, somadas à precariedade do serviço, culminavam na culpabilização das mulheres em situação de violência. Os/as entrevistados/as apontaram a necessidade de criação de um serviço de Psicologia para apoio às mulheres e aos/às próprios/as policiais. Neste sentido, propõe-se a implantação de formação dos/as trabalhadores/as da DEAM e a realização de intervenções psicossociais, de modo a potencializar o papel da polícia no enfrentamento da violência de gênero.
\end{abstract}

Palavras-chave: violência doméstica; polícia; psicologia; gênero.

\section{Experiences of police officers from a DEAM in the Southwest of Goiás}

\begin{abstract}
The research investigated the experiences of civil police officers of a Specialized Police Station for Women's Care (DEAM) in a municipality in the southwestern region of Brazil in the care of women in situations of domestic violence. Based on the qualitative approach, semi-structured interviews were conducted with four police officers, two women and two men. Several difficulties experienced in daily professional life were found, from lack of physical space, employees and time, to the absence of training to meet women. Although they had knowledge about the Maria da Penha's Law, the participants reproduced sexist and misogynistic gender conceptions that, added to the precariousness of the service, culminated in blaming women in situations of violence. The interviewees pointed out the need to create a Psychology service to support women and the own police officers. In this sense, DEAM workers should be properly trained, and there should be the performance of psychosocial interventions, in order to enhance the role of the police in coping with gender violence.
\end{abstract}

Keywords: domestic violence; police; psychology; gender.

\section{Introdução}

A violência doméstica constitui-se em problema de escala mundial e atinge as mulheres com formas e intensidades específicas ao considerar os marcadores sociais de cor, etnia, credo, gênero, orientação, identidade ou idade. Tem sido pauta de diversas discussões desde a última década do século XIX, apesar de ser uma questão social muito mais antiga (GUIMARÃES; PEDROZA, 2015). A violência doméstica é fruto das históricas e sociais desigualdades de gênero e pode ser entendida como uma relação de poder de dominação do homem e de submissão da mulher (SOUZA, M.; SOUZA, T., 2019; SOUZA, T.; SANTANA; MARTINS, 2018).

O gênero é uma categoria analítica e política que auxilia na compreensão dos papéis sociais desempenhados a partir do sexo biológico determinado no momento do nascimento (SCOTT, 1995). Partindo dessa perspectiva, historicamente o homem tem sido colocado como ser dominante, racional, destinado à esfera pública, ao trabalho remunerado, à tomada de decisões em relação à família. Já a mulher tem sido vista como submissa, emocional, destinada à esfera privada, ao cuidado da família e aos afazeres domésticos (PIOSIADLO; FONSECA; GES-

\footnotetext{
^Endereço para correspondência: Universidade Federal de Catalão, Instituto de Biotecnologia. Avenida Doutor Lamartine Pinto de Avelar, 1120 - Loteamento Vila Chaud - Catalão, GO - Brasil. CEP. 75704-020. E-mail: tatimachiavellie yahoo.com.br, thaisferreiramartins@outlook.com.br

Os dados completos das autoras encontram-se ao final do artigo.
}

SNER, 2014). Logo, os papéis socialmente construídos pela cultura e religião carregam a ideia de que o homem mantém o poder sobre a mulher, com o direito de dominá-la e oprimi-la, violentando-a de diversas maneiras. As questões de gênero são estruturantes da condição subjetiva dos indivíduos e da organização das relações sociais, que se estabelecem com desigualdades de poder e viabilizam a violência doméstica (GUIMARÃES; PEDROZA, 2015).

Os motivos que levam muitas mulheres a permanecerem em situações de violência e não denunciarem as agressões são os mais variados. Nem sempre é por dependência econômica e/ou emocional (SOUZA, T.; SABINI, 2015). Há também o fato de se acharem merecedoras de punição e infelicidade por não terem cumprido devidamente tarefas que acreditam ser de sua exclusiva responsabilidade. Deste modo, acabam por se culpar pela violência que sofrem e mantêm-se nessas relações com a ideia de que as merecem (DIAS, 2012). Reiterando a cultura de culpabilização das mulheres, Moraes e Ribeiro (2012), em pesquisa com grupos reflexivos junto a homens autores de violência doméstica, verificaram que eles, ao explicarem as agressões, conferem à violência um caráter de punição ao comportamento "inadequado" das mulheres que, em suas opiniões, estavam descumprindo seus papéis, rompendo com os costumes historicamente 
estabelecidos e aceitos. Foi observado ainda que, de modo geral, os homens responsabilizavam as mulheres, seja totalmente ou parcialmente, pela agressão cometida.

Durante as últimas décadas, a partir das diversas mobilizações feministas, a realidade das mulheres no Brasil vem sendo modificada, o que pode ser confirmado com a criação de Lei 11.340 (BRASIL, 2006), conhecida como Lei Maria da Penha (SOUZA, M.; SOUZA, T., 2019). A referida lei criou mecanismos para evitar, prevenir e enfrentar a violência doméstica, estabelecendo punições para os agressores e medidas protetivas e assistenciais para as mulheres em situação de violência. Também propõe políticas de prevenção voltadas para a sociedade, a fim de erradicar práticas violentas, que podem ser físicas, psicológicas, sexuais, patrimoniais ou morais.

A Lei Maria da Penha também promoveu avanços ao definir a violência doméstica pelo uso de força física, psicológica ou intelectual para obrigar ou induzir uma pessoa a fazer algo que não queira; trata-se de qualquer ação ou conduta no sentido constrangê-la, restringi-la incomodá-la, oprimi-la, coagi-la, violá-la, ameaçá-la, submetê-la ao seu domínio (BRASIL, 2006). Nesse sentido, a violência física se caracteriza por ofender a integridade física da vítima; a psicológica, por danos emocionais, diminuição da autoestima, ridicularização, chantagem, controle sobre a mulher e humilhação; a sexual, por condutas que obriguem a mulher a estabelecer, presenciar, comercializar relações sexuais sem seu consentimento, ou que limitem ou anulem o exercício de seus direitos sexuais e reprodutivos; a patrimonial, por danos a bens materiais pertencentes à vítima; e a moral, por condutas que caluniem, difamem ou injuriem a vítima (BRASIL, 2006).

Para cumprir os objetivos a que se dispõe, a Lei Maria da Penha conta com o auxílio das Delegacias Especializadas de Atendimento à Mulher (DEAMs), criadas a partir de 1985, fruto de lutas feministas visando ao enfrentamento da violência doméstica e à assistência para as mulheres (BANDEIRA, 2014). Essas delegacias devem ofertar um atendimento multidisciplinar às mulheres e buscar garantir seus direitos nas relações domésticas e familiares, assim como resguardá-las de qualquer tipo de negligência, discriminação, exploração, violência, crueldade e opressão (SOUZA, M.; SOUZA, T., 2019; SOUZA, T.; SANTANA; MARTINS, 2018).

Mesmo com a existência das DEAMs, da Lei Maria da Penha, das Centrais de Atendimento à Mulher (Disque 180 - serviço de orientação às mulheres sobre seus direitos, encaminhando-as para outros atendimentos quando necessário) e de outros mecanismos de proteção às mulheres, pouco pode ser feito se os/as profissionais não forem capacitados para trabalhar com a violência doméstica e se abdicarem das concepções desiguais em relação ao gênero. A existência de políticas para a formação e capacitação de policiais e outros/as profissionais não tem garantido estratégias nessa direção, especialmente em cidades interioranas. Estudos apontam que há necessidade de formação profissional e continuada para operadores/ as da lei e técnicos/as especializados/as no atendimento às mulheres em situação de violência (PASINATO, 2015;
SOUZA, M.; SOUZA, T., 2019; SOUZA, T.; REZENDE, 2018; SOUZA, T.; SANTANA; MARTINS, 2018; SOUZA, T.; SOUSA, 2015).

Em relação aos/às profissionais que atuam nas delegacias, vale lembrar que pertencem à sociedade predominantemente machista e patriarcal e, possivelmente, possuem concepções desiguais de gênero já constituídas em suas subjetividades, e isto se reflete na atuação profissional. A falta de qualificação no atendimento policial é um fator contribuinte para a diminuição das denúncias por parte das mulheres, que buscam nas delegacias uma forma de apoio e solução para o sofrimento em que vivem. $\mathrm{O} / \mathrm{a}$ profissional que não possibilita o acolhimento, a escuta e o olhar diferenciado, entendendo os contextos em que a violência ocorre, está legitimando a violência doméstica, mantendo-a invisível e impune, além de destruir as esperanças das mulheres de encontrar uma solução para seu sofrimento (BANDEIRA, 2014).

Da mesma forma, Nunes (2012), ao retratar a perspectiva de policiais civis frente à violência doméstica, constatou que eles/as se sentiam incapacitados/as para lidar especificamente com o tema e sofriam pela falta de uma rede de atendimento eficiente. Além destes fatores, os/as policiais também relataram que as condições de trabalho interferem no atendimento prestado às mulheres, como, por exemplo, a falta de recursos tecnológicos, materiais e humanos, estado emocional debilitado dos/ as funcionários/as, sentimentos negativos em relação ao trabalho, salários baixos, alta carga horária de trabalho, dentre outros. Capelle e Melo (2010) verificaram que a capacitação tradicional do/a policial, voltada para uma postura rígida e agressiva, é inadequada para a atuação frente à violência doméstica, já que estes casos necessitam de uma postura mais acolhedora e humanitária. Outro fator que contribui para a precária qualidade do atendimento policial é a naturalização dos casos de violência doméstica. Após terem intenso e cotidiano contato com a violência, acabam naturalizando-a e tornando-se insensíveis à situação (CAPELLE; MELO, 2010).

O trabalho policial no atendimento das mulheres em situação de violência transcende a dimensão técnica e demanda uma rede de atendimento intersetorial competente. Nesse contexto, a Lei 11.340 (BRASIL, 2006) propõe a disposição e intervenção de uma equipe multidisciplinar para oferecer assistência às mulheres. Essa medida é de suma importância, já que estudos indicam que mulheres em situação de violência doméstica podem apresentar, além das marcas físicas, inúmeros outras expressões do sofrimento. Essas podem se refletir em distúrbios gastrointestinais, distúrbios do sono, estresse, baixa autoestima, bem como ansiedade, depressão, tendências suicidas, entre outros (GOMES et al., 2012).

Monteiro (2012), em estudo sobre o papel da psicologia no atendimento às mulheres e aos autores de violência doméstica, afirma que o trabalho deve ter como objetivo o resgate da condição de sujeito das mulheres, de sua autoestima, desejos e vontades, os quais ficam anulados e encobertos no contexto de violência doméstica. Para isso, deve-se oferecer uma escuta acolhedora e ativa, propondo 
intervenções para que as mulheres reconheçam a relação violenta que vivenciam, não a naturalizando; entendendo que não são culpadas pelas violências que sofrem. O processo de acolhimento deve também ressignificar a concepção que as mulheres possuem em relação às agressões do parceiro, sem os processos de negação, a fim de empoderá-las para que possam transformar ou sair da situação de violência, descobrindo formas de lutar pelos seus direitos, realizarem seus desejos e objetivos de vida (MONTEIRO, 2012). Aqui, o conceito de empoderamento está intimamente vinculado ao fortalecimento de vínculos sócioafetivos, de trabalho, assim como de outras estratégias de emancipação social; portanto, não se trata da ideia de dar poder unicamente à mulher, em uma perspectiva individualizante. Ao contrário, trata-se de construir movimentos coletivos de resistência e luta em direção à garantia de direitos, conforme aponta Baquero (2012).

Nesse sentido, a Lei Maria da Penha não responsabiliza apenas o Estado, mas sim toda a sociedade, demandando políticas públicas educativas, em saúde, assistência social, segurança pública, entre outras, que possam impactar e transformar as mentalidades, atitudes e práticas culturais, de modo que homens e mulheres sejam capazes de se socializarem de forma equitativa e igualitária. Em vista das problemáticas citadas neste texto, o presente estudo buscou conhecer as vivências de policiais civis do município de Jataí/GO, investigando as concepções de violência doméstica e o cotidiano de trabalho no atendimento às mulheres, problematizando o papel das DEAMs e da psicologia nestes contextos.

\section{Metodologia}

Trata-se de pesquisa qualitativa com aprovação do Comitê de Ética e Pesquisa da Universidade Federal de Goiás, sob o $n^{\circ} 2.916 .536$. Foi realizada em uma Delegacia Especializada de Atendimento à Mulher do município de Jataí, no sudoeste goiano. Participaram do estudo quatro policiais civis, conforme Quadro 1. Foi solicitada a anuência por meio de Termo de Consentimento Livre e Esclarecido. As identidades dos/as participantes foram mantidas em sigilo por meio do uso de abreviações.

Quadro 1 - Informações dos/as entrevistados/as conforme autodeclaração

\begin{tabular}{|c|c|c|c|c|}
\hline Participantes & $\mathrm{A}$ & B & $\mathrm{C}$ & $\mathrm{D}$ \\
\hline Sexo & Feminino & Feminino & Masculino & Masculino \\
\hline Idade & 34 & 43 & 38 & 38 \\
\hline Estado civil & Casada & Casada & Casado & Casado \\
\hline Filhos & 1 & 2 & 2 & 1 \\
\hline Religião & Católica & Espírita & Católico & Católico \\
\hline Grau de escolaridade & Especialização & Especialização & Especialização & Ensino Superior \\
\hline Cor & Parda & Parda & Pardo & Pardo \\
\hline Carreira policial & Escrivã & Agente Policial & Escrivão & Delegado \\
\hline $\begin{array}{c}\text { Tempo de atuação na } \\
\text { Polícia Civil }\end{array}$ & 2 anos & 16 anos & 16 anos & 2 anos \\
\hline
\end{tabular}

Fonte: Elaboração das autoras
Os dados foram obtidos através de entrevistas semiestruturadas, realizadas entre os meses de novembro e dezembro de 2015. Estas se propuseram a investigar a concepção de violência doméstica, as condições de trabalho, o papel da DEAM no enfrentamento à violência doméstica, as (im)possibilidades de intervenção psicológica na DEAM e as possíveis ações frente às mulheres em situação de violência e aos autores de agressão. As entrevistas apresentavam quatro partes: a) identificação dos sujeitos; b) carreira e atuação na Polícia Civil; c) concepções sobre violência doméstica e prática profissional na DEAM; e d) levantamento de crenças sobre a violência doméstica. No item "d" da entrevista foram apresentadas frases de trabalhos científicos e ditados populares relacionados à temática abordada no presente estudo, e os/ as entrevistados/as foram convidados/as a classificarem as afirmações como verdadeiras ou falsas e justificarem seu posicionamento. As entrevistas foram audiogravadas e, posteriormente, transcritas na íntegra.

A interpretação dos dados foi realizada a partir da análise de conteúdo (BARDIN, 1977), a qual se constitui por várias técnicas que buscam descrever o conteúdo emitido no processo de comunicação. É utilizada partindo-se do princípio de que o foco do estudo é qualificar as vivências do sujeito e suas percepções sobre determinado objeto e seus fenômenos. O método se constitui em três etapas: pré-análise (leitura flutuante); exploração do material (análise exaustiva do material e problematizações); tratamento dos resultados obtidos e interpretação. Para a discussão, realizou-se a classificação e agregação dos dados, escolhendo as categorias teóricas ou empíricas, responsáveis pela especificação do tema (BARDIN, 1977). A partir disto, foram feitas inferências e interpretações, dando origem às seguintes categorias: a) Concepções sobre a violência doméstica; b) Práticas pertinentes às DEAMs; e c) (Não)Culpabilização das mulheres.

\section{Resultados e discussões}

\section{Concepções sobre a violência doméstica}

Os/as entrevistados/as definiram a violência doméstica como todo e qualquer comportamento que "desrespeite" as mulheres em sua integridade física, emocional e em sua honra. Referenciaram também a Lei 11.340 (BRASIL, 2006), citando as tipificações da violência como física, psicológica, moral, patrimonial e sexual. Apesar de contarem com as definições contidas na citada lei, os discursos tendiam a não estratificar os tipos de violência, mas 
sim a abordá-los de maneira inter-relacionada, apontando para um "contexto violento", no qual diversas formas de violência ocorrem. Pesquisas apontam para este mesmo fato, ressaltando que um tipo de violência doméstica não ocorre isoladamente, mas as diversas agressões ocorrem imbricadas (DEEKE et al., 2009).

[...] Violência doméstica está relacionada não só à violência física, mas também à violência psicológica, financeira... porque muitas vezes a gente percebe que a mulher não vem denunciar porque ela se sente dependente financeiramente do homem, ou até mesmo por uma fragilidade psicológica dela, de autoestima... (Participante A).

[...] Raramente a violência começa numa agressão física. Às vezes, antes disso, já existe uma agressão psicológica, uma injúria, uma ameaça. Quando a mulher procura a delegacia, é porque já extrapolou (Participante B).

A dependência financeira, como justificativa para a permanência das mulheres em um relacionamento violento, prevaleceu nos discursos. Os/as participantes apontaram a preocupação das mulheres com o sustento dos filhos, a possibilidade de não ter moradia, a falta de capacitação profissional e de subsídios para se manter em uma jornada de trabalho como os motivos mais relevantes e frequentes para que as mulheres permaneçam com o companheiro que a agride, o que também foi constatado por outros/as autores/as (MIZUNO; FRAID; CASSAB, 2010; PORTO; BUCHER-MALUSCHKE, 2014; SOUZA, T.; SABINI, 2015).

[...] essa mulher, mesmo sendo vitima, ela sente dificuldade de deixar esse companheiro. Por que ela se preocupa como é que vai ser, onde ela vai morar, como vai ser a criação dos filhos. Às vezes ela não sente força para sair dessa relação, muito mais por conta de uma questão material (Participante C).

De modo antagônico, houve discursos que, mesmo considerando as dificuldades existentes em relacionamentos violentos, apontaram que as mulheres podem rompê-los, a partir do seu desejo. Essa concepção parece um tanto simplista e estereotipada, já que muitos outros fatores estão envolvidos nas relações conjugais. Mizuno, Fraid e Cassab (2010) assinalam as questões de ordem financeira, assim como a falta de um emprego que garanta o sustento para as mulheres e filhos/as, como fortes motivos para que elas permaneçam com o agressor. Outros fatores, contudo, também se mostram relevantes nessas situações, como, por exemplo, a vergonha e o constrangimento em relação à opinião pública, amigos e família; a culpa por não conseguir manter a relação; a dependência emocional e afetiva em relação ao companheiro, entre outros (MIZUNO; FRAID; CASSAB, 2010; SOUZA, T.; SABINI, 2015). Psicólogos/as que atendem mulheres que sofreram violência doméstica reiteram que muitas se anulam pelos/as filhos/as e pela família, e permanecem no relacionamento na tentativa de "consertá-lo" e de ter suas expetativas de "amor romântico" realizadas (PORTO; BUCHER-MALUSCHKE, 2014).

As agressões moral e psicológica foram apontadas como tão violentas quanto outras tipificações. Os discursos apresentaram a violência moral e psicológica como feridas que não se fecham, mesmo com o passar do tempo, e as consequências psicológicas destas agressões como sendo capazes de interferir em todos os contextos de vivências da mulheres, comprometendo sua saúde e desenvolvimento social. Observou-se contradição nas falas dos/ as participantes, que ora reconheciam valor nas violências moral e psicológica, ora colocavam a agressão física como o tipo máximo de violência doméstica, hierarquizando e diminuindo a relevância de outros tipos de agressão.

\section{[...] Então, eu acho que a mulher que está sofrendo vio- lência fisica, todo dia, ela tem que procurar ajuda (Parti- cipante A).}

[...] Se o casal continuar junto, pode até ser que tenha uma consequência mais grave, uma lesão corporal (Participante D).

Em relação às possibilidades de enfrentamento e superação do relacionamento violento, os/as entrevistados/as apontaram opiniões distintas. Alguns/ mas afirmaram que a única solução seria a separação, pois em uma situação de violência haveria a perda do respeito, que não poderia ser recuperado. Em contrapartida, foi ressaltada a ideia de que sempre há estratégias de mudanças e melhorias na relação. De modo particular, foi exposto que, se a violência decorre de fatores externos, como o uso de álcool, drogas, entre outros, seria possível fazer algum tratamento e restabelecer a saúde da relação; contudo, se a violência decorre de problemas pessoais ou inerentes à relação do casal, a única solução seria a separação. Outras possibilidades, como intervenções psicológicas e sociais junto aos agressores, a adoção de práticas com viés punitivista ou a busca de justiça e reparação da experiência violenta de outras formas, não foram sinalizadas pelos/as participantes.

\section{Práticas pertinentes às DEAMs}

A delegacia foi descrita como ambiente inadequado para o atendimento das mulheres em situação de violência e citada como uma dentre as maiores dificuldades encontradas no trabalho. Em relação à sala em que as mulheres são atendidas, na qual atuavam duas escrivãs e um escrivão, os/as entrevistados/as relataram não haver possibilidade de um atendimento particular, sigiloso, que pudesse acolher a denúncia de modo apropriado. Os discursos afirmaram que as mulheres, ao chegarem ao dispositivo policial, já estão fragilizadas pela violência que sofreram e precisam encontrar um ambiente de proteção e acolhimento. Este tipo de atendimento se torna impossível no espaço físico existente, o qual pode constrangê-la.

\footnotetext{
[...] Então há uma dificuldade de poder ouvir a pessoa de uma forma mais velada, mais tranquila, mais privada, de modo a não constrangê-la pelo problema que ela vem trazer. [...] Normalmente a pessoa já vem tão conturbada com o que ela sofreu que, para ela externalizar isso na presença de outras pessoas, fica mais dificil (Participante C).

[...] O trabalho aqui é muito importante, porque tem aquele apoio, aquele amparo que você vai dar pra mulher, ela já está fragilizada em razão da violência sofrida. Então é muito importante aquela atenção, atendê-la de uma forma que ela se sinta protegida e veja que alguém está preocupa-
} 


\section{do com o problema dela (Participante D).}

Como exemplo deste cerceamento, as mulheres podem estar sendo atendidas por uma profissional (mulher) e se sentir envergonhadas por ter um escrivão (homem) na sala. Pode ocorrer também o fato de serem atendidos simultaneamente agressores e vítimas, o que foi considerado como doloroso e constrangedor. Esta situação não é restrita somente à DEAM pesquisada. Estudos apontam que, em casos de flagrante, vítima e agressor são atendidos na mesma sala e que a maioria das DEAMs do país não possui espaço adequado para o atendimento individual dos relatos de violência. Há ainda a precariedade dos espaços físicos, com número de salas insuficiente perante as demandas das DEAMs, que usualmente são: atendimento às mulheres de modo individual e privado; atendimento do autor da agressão de modo separado; ambiente para a permanência dos/as filhos/as para que não tenham contato com o relato de violência; sala própria de espera distinta para mulheres e agressores (ANDRADE, 2012; CORTEZ, 2012; PAIXÃO, 2013).

Relataram-se casos em que as mulheres se dirigem à delegacia para efetivar a queixa acompanhada dos/as filhos/as, os quais, em virtude da falta de um local reservado para sua permanência, acompanham as respectivas mães, ouvindo o relato da agressão. Esse fato foi considerado pelos/as entrevistados/as como prejudicial às crianças, principalmente porque, se elas presenciarem agressão, estarão rememorando e vivenciando algum nível de sofrimento.

A falta de conhecimento e de preparo para prestar atendimento às mulheres também foi citada como uma dificuldade da DEAM. Os/as participantes apontaram ser essencial às mulheres que procuram a ajuda da polícia receber atendimento diferenciado, em um contexto que seja capaz de apreender as suas necessidades; contudo não se sentiam preparados/as para isso. Somente uma das entrevistadas havia recebido um curso de capacitação para o trabalho de atendimento às mulheres em situação de violência doméstica. Embora a realização de um curso não seja suficiente para a melhoria do atendimento, houve o relato de que o trabalho prático poderia fornecer capacitação. É certo que a prática pode propiciar melhoria do serviço prestado, entretanto uma atuação destituída de reflexão crítica e de embasamento teórico-metodológico pode servir à reprodução de concepções presentes no senso comum.

O acolhimento e orientações são demandas diárias vivenciadas no contexto de uma DEAM; porém, a literatura aponta que a maioria dos/as funcionários/as não recebe nenhum tipo de capacitação e se veem com muitas fragilidades para conduzir os atendimentos de maneira humanizada (PASINATO, 2015; SOUZA, M.; SOUZA, T., 2019; SOUZA, T.; REZENDE, 2018; SOUZA, T.; SANTANA; MARTINS, 2018; SOUZA, T.; SOUSA, 2015). Nesse contexto, o apoio psicológico às mulheres é importante diante da demanda existente nas DEAMs (ANDRADE, 2012; CORTEZ, 2012; PAIXÃO, 2013).
Os discursos estavam impregnados de queixas em relação ao pequeno número de funcionários/as e à grande demanda de trabalho, cujo cumprimento de prazos seria cobrado pelo Ministério Público. Assim, os/as participantes se viam impossibilitados/as de dispor do devido tempo para o acolhimento às mulheres, reduzindo seu trabalho ao cumprimento de protocolos, registro da ocorrência e produção do processo jurídico. Essa realidade também é presente na maioria das DEAMs, pois funcionam com um número de funcionários/as reduzido em relação ao que seria adequado à demanda. Para além da escassez de recursos humanos, existe ainda a carência de pessoas em cargos específicos; nem sempre há, por exemplo, recepcionista, psicólogo/a, assistente social, dentre outros/as técnicos/as importantes nesses ambientes (CORTEZ, 2012; OBSERVE, 2010; PAIXÃO, 2013).

Outra dificuldade apresentada pelos/as participantes foi a ausência de casa de abrigo para as mulheres que residem com o agressor e sofrem ameaças quando tentam sair da casa. A falta de ambiente seguro para o abrigamento enquanto são tomadas as medidas em relação ao agressor pode impedir as mulheres de denunciarem a violência que sofrem, em virtude do medo da reação do parceiro no ambiente domiciliar. Os discursos reconheceram que a inexistência do serviço faz com que as mulheres deixem de procurar ajuda na delegacia, por não acreditarem na justiça, na proteção policial e na punição do agressor. Mesmo assim, foi relatado que há grande procura de atendimento na DEAM, com alto índice de boletins registrados.

Os/as entrevistados/as expressaram que a rotina de trabalho na DEAM gera a naturalização dos casos de violência, e as mulheres se tornam "só mais uma vítima". De modo paradoxal, também afirmaram que os relatos das mulheres os/as atingem intimamente, muitas vezes provocando sentimentos e emoções dolorosas, afetando sua rotina de trabalho e eficiência no decorrer dos atendimentos. Assim, como afirma Paixão (2013), a violência parece atravessar o cotidiano dos/as policiais na DEAM, tanto pelas condições de trabalho quanto pelo contato diário com conflitos e sofrimento humano. $\mathrm{O}$ ambiente da delegacia pode ser muito desagradável, frente às demandas institucionais, o desamparo das mulheres em situação de violência e o frequente sentimento de impotência dos/ as policiais diante dos relatos.

[...] muitas vezes, a violência sofrida pelas mulheres nos atinge psicologicamente e a gente vai embora com aquele clima pesado... (Participante B).

[...] Infelizmente, eu acho que isso é natural depois de algum tempo, a gente começa a ver cada vítima como "só mais uma vítima". Então é difícil pra gente. Seria meio que uma naturalização do problema, pelo fato de a gente conviver diariamente com essas situações [...] O apoio psicológico seria importante para desempenhar melhor o trabalho e não levar toda aquela carga de problemas até para a vida pessoal mesmo (Participante C). 
Deste modo, o apoio psicológico foi citado como forma de auxiliar na elaboração e alívio dos sentimentos que emergem na rotina policial e evitar que os problemas do trabalho sejam externados a outras dimensões da vida social, como o convívio familiar. Questionados/as sobre o papel da psicologia na DEAM, os/as participantes afirmaram que seria útil na atuação junto às mulheres, aos agressores, seus/suas filhos/as e familiares, e para a equipe da instituição.

Em relação ao trabalho da psicologia com as mulheres em situação de violência, os/as entrevistados/as apresentaram perspectivas distintas. Nesse sentido, o acompanhamento psicológico seria importante para identificar algum tipo de "insanidade" na mulher, problemas psicológicos e a possibilidade de que o relato de violência se dê a partir de alucinações. Assim, a/o psicóloga/o poderia julgar o que deveria ser registrado no processo judicial, podendo evitar a punição de um homem inocente. Nestes casos, os discursos estavam impregnados de concepções que psicopatologizavam as mulheres e articulados com o lugar da/o psicóloga/o como perita/o. Esse ponto de vista apresentado pelos/as participantes se distancia significativamente das ações propostas pelas políticas públicas. Compete à psicologia, no cenário da DEAM, acolher e auxiliar mulheres e homens a lidar com a violência presente na relação conjugal, de modo que sejam capazes de desenvolver condições de suplantá-la (BRASIL, 2010).

Vale ressaltar que o sentimento de descrédito do/a policial em relação ao relato é passível de gerar um mal atendimento e até mesmo negligência frente às queixas das mulheres; com isso, faz-se necessária a ampliação da percepção do/a policial em relação à violência doméstica, de modo a compreender os contextos e repercussões que esta adquire na experiência das mulheres. O papel de julgar o relato de violência, atribuído à/ao psicóloga/o é uma responsabilidade que não concerne a este serviço. Estudos mostram que essa/e profissional, diversas vezes, é alocada/o nas triagens das vítimas, explicação dos procedimentos, entre outras tarefas que não condizem com a profissão, demonstrando a falta de conhecimento dos/as policiais frente à atuação psicológica (CORTEZ, 2012).

O sentimento de culpa vivenciado por algumas mulheres foi referenciado pelos/as participantes como um aspecto que as impede de assumirem-se assujeitadas aos agressores. Assim, além de possibilitar a compreensão de sua situação de vítima, a/o psicóloga/o atuaria de modo a empoderar as mulheres, para que elas tenham condições de ressignificar sua experiência (MONTEIRO, 2012).

[...] O trabalho do psicólogo seria importante pra que ela se sinta em condições de seguir a vida e entender que aquele problema não retira sua capacidade de viver, não retira até mesmo sua vontade de continuar, de prosseguir a vida (Participante D).

$\mathrm{O}$ apoio psicológico também incluiria a atividade de escuta, de modo a acolher o sofrimento das mulheres. Os relatos apontaram que elas chegam à delegacia com muitos problemas, com necessidade de conversar e, como os/ as policiais não dispõem de tempo nem preparo para isso, a/o psicóloga/o desempenharia esse papel. A necessidade de conversar, em detrimento do estrito registro de boletins de ocorrência, foi citada também por Cortez (2012) e Paixão (2013). Cortez (2012) verificou que funcionários/ as da maioria das DEAMs realizam trabalhos extrajudiciais, concebendo-os como acolhimentos, mediações de conflitos e escuta de relatos emocionais. Ainda que estas práticas não façam referência ao trabalho policial, entende-se que são pertinentes às DEAMs e que o/a funcionário/a deve ter uma capacitação diferenciada do policial civil comum e voltada para a compreensão e acolhimento do fenômeno da violência doméstica.

\section{[...] a maior parte dessas mulheres chegam com muitos pro- blemas e precisam realmente de conversar. Às vezes preci- sam muito mais de conversar do que do simples registro do boletim de ocorrência. E esse atendimento com o psicólogo poderia dar um amparo e conforto pra ela (Participante $\mathrm{C}$ ). \\ [...] eu acredito que se ela tivesse um amparo psicológico pra estar entendendo o que acontece com ela, e até pra ela reagir melhor ao que está passando, o psicólogo seria necessário (Participante A).}

Apesar dos/as entrevistados/as terem ressaltado a importância de apoio às mulheres, pode-se ainda observar uma tendência a diminuir suas capacidades. Assim, como afirma Bandeira (2014), o profissional que não possibilita a escuta e o acolhimento, entendendo os contextos em que a violência ocorre, está legitimando a violência, mantendo-a invisível e suprimindo as esperanças das mulheres em relação à eficácia judicial.

\section{[...] Dependendo da forma como você fala, pode diminuir ainda mais aquela pessoa fragilizada com uma situação que veio do convívio dela com o companheiro. Então, de- pendendo dos valores do policial, essa pessoa pode sim, novamente, ser vítima na delegacia, sofrer mais um tipo de violência (Participante $\mathrm{C}$ ).}

Uma prática comum relatada pelos/as entrevistados/ as foi a orientação fornecida às mulheres. Ao recebê-la pela primeira vez na delegacia, explicam os procedimentos sobre o registro do boletim, a possibilidade de escolher a representação judicial ou não, a existência de medidas protetivas, entre outros. Dessa forma, é permitido que as mulheres façam a retirada da queixa, e isso tem sido frequente no dia a dia do serviço, suscitando indignação dos/as policiais frente à circunstância. Ademais, relataram não entender casos em que as mulheres denunciam a agressão sem ter interesse de se separar do parceiro ou de que ele vá preso. Portanto, são privilegiadas orientações que consistem em tentar convencer as mulheres de que, ao permanecerem no relacionamento, continuarão sendo agredidas ou, se não resolverem sua situação, corrigirem o que estaria gerando as agressões, registrar inúmeros boletins de ocorrência, não sanarão as violências. Essas posturas parecem conflitantes com a Lei Maria da Penha e com as políticas públicas da área, pois as mulheres têm o direito de se retratar em casos de ameaça, bem como de permanecer com o cônjuge violento (PASINATO, 2015). As orientações são importantes, 
mas induzir a vítima a romper o relacionamento pode ser tão violento quanto as demais violências infringidas no convívio doméstico.

Silva (2012) aponta que posturas de negociação e mediação são práticas comuns em diversas DEAMs do país, e que os policiais se veem na capacidade de orientar as mulheres para uma tomada de decisão. Essas mediações podem se constituir em um risco para a garantia dos direitos individuais das mulheres, principalmente sendo exercidas sem nenhum respaldo em técnicas de mediação voltadas para a manutenção da integridade moral e física delas.

\section{(Não) Culpabilização das mulheres}

Os/as participantes apresentaram contradições, ora afirmando que as mulheres poderiam induzir situações provocadoras da agressão perpetrada pelo parceiro, ora alegando que ela é vítima da violência e que quaisquer atitudes não justificariam a agressão. Foi apontado que muitas mulheres não desejam permanecer no relacionamento, porém alimentam expectativas quanto a mudanças no comportamento do parceiro ou acabam se relacionando com outros homens. Este exemplo carrega tanto uma perspectiva judicial retrógrada, que remonta ao início do século passado, quando era permitido que o marido violentasse a esposa adultera como "defesa da honra" (SANTIAGO; COELHO, 2010), quanto relações desiguais de poder estabelecidas pela cultura ao longo da história, nas quais o homem tem domínio sobre a mulher, como uma posse, como um ser sem identidade, feito para lhe satisfazer e obedecer (BANDEIRA, 2014; GUIMARÃES; PEDROZA, 2015).

Outro fator apresentado pelos/as entrevistados/as foi a possibilidade de as mulheres provocarem a agressividade do homem, irritá-lo de diversas maneiras com o objetivo de que ele a agrida fisicamente e elas tenham marcas para registrar um boletim de ocorrência.

[...] Ela ataca para que o homem a ataque e deixe marcas nela, pra ela poder vir registrar [...] Muitas mulheres se aproveitam da lei para provocar algum tipo de reação por parte do homem (Participante B).

[...] A gente percebe que elas poderiam ter tido outro comportamento, que, de repente, não resultaria num caso de violência doméstica (Participante $\mathrm{C}$ ).

Caso verdadeiras, essas práticas relatadas pelos/as policiais podem apontar a vulnerabilidade em que as mulheres se encontram, sem recursos para se defender, apelando para medidas extremas, infringindo sua própria integridade física na tentativa de obter respaldo jurídico. Também representa uma denúncia ao sistema judicial, que negligencia a violência que acomete tantas mulheres cotidianamente em seus lares.

Os discursos também apontaram que as mulheres podem evitar ser agredidas, apresentando comportamentos diferentes. Em momento algum o homem foi citado como transgressor ou desrespeitoso com as mulheres. A ideia de que elas mereceram as agressões ou de que estas foram inevitáveis, frutos dos seus comportamentos, foi expressa frequentemente. Neste sentido, verificam-se as desigualdades de gênero enraizadas na cultura machista. Historicamente, são atribuídas ao homem características como impulsividade, agressividade e poder. Supõe-se que as mulheres, ciente dessas características, devem se esforçar para não as despertar, mantê-lo estável e garantir sua segurança pessoal (PIOSIADLO; FONSECA; GESSNER, 2014).

[...] Acontece que, quando a mulher não se respeita, não se valoriza, ela deixa que determinados tipos de violência lhe aconteçam (Participante B).

Os/as entrevistados/as também expressaram que as mulheres permitem ser agredidas. Essa permissão foi explicada com base numa falta de respeito em relação a si mesma e na falta de autovalorização. Estes discursos excluem as repercussões que definições desiguais de papéis e poder atribuídas ao gênero adquirem na constituição do sujeito (SCOTT, 1995). Fatores culturais e a própria educação familiar inserem nas mulheres o dever de cuidar de casa, dos/as filhos/as e até mesmo a necessidade de se anular para atender às vontades do homem e obedecer-lhe. Precocemente, as mulheres são ensinadas pela família, pela igreja, pela escola, a abdicar de seus desejos em benefício dos desejos do homem, tornando-se incapaz de recusar e até mesmo reconhecer a violência doméstica. Esses fatores estavam excluídos das concepções dos/as entrevistados/as, o que contribui para a culpabilização das mulheres.

\section{Considerações finais}

O presente estudo investigou as vivências de policiais civis da Delegacia Especializada de Atendimento à Mulher (DEAM) em um município do sudoeste goiano, buscando conhecer as concepções de violência doméstica e problematizando o papel das DEAMs e da psicologia nestes contextos. Verificou-se que os/as participantes compreendem a violência doméstica como experiência ancorada nas desigualdades entre homens e mulheres e que a dependência financeira atua como forte empecilho para o rompimento da relação. A afirmação das mulheres como sujeitos de suas vontades e desejos também foi apontada como um elemento que pode impulsionar o rompimento da relação violenta, o que reflete uma visão limitada das questões culturais, sociais e históricas que tangenciam a violência doméstica. Os relatos apresentaram concepções antagônicas sobre a violência, ora colocando as mulheres como responsáveis pela violência que sofrem e, portanto, delegando-lhes a competência exclusiva para tomarem atitudes, a fim de evitar e romper essa situação, ora destacando a ideia de que as mulheres não devem se culpar pelas agressões sofridas. Em nenhum momento foi exposto algum tipo de repúdio ou repreensão à postura do autor de agressão.

Problemas em relação à falta de espaço físico, funcionários, tempo e capacitação foram apontados como dificuldades para a realização de atendimento e acolhimento adequado às mulheres em situação de violência. Foi sinalizado que o contato diário com a violência provoca a naturalização desse fenômeno, o que acomete a qualidade do trabalho. Os/as policiais se sentem envol- 
vidos/as e sensibilizado/as, o que afeta seu desempenho no cotidiano do serviço e nas relações familiares. Neste sentido, a atuação psicológica na delegacia poderia auxiliar na promoção da saúde dos trabalhadores, bem como no atendimento e acolhimento das mulheres. Contudo, percebeu-se uma visão distorcida sobre o papel e o lugar da psicologia nesse contexto.

A pesquisa possibilitou uma compreensão sobre o ambiente e os/as policiais que atuam na DEAM. Pode ser utilizada como ponto de partida para o investimento na capacitação sobre violência doméstica, gênero, feminismo, machismo, patriarcado, dentre outras temáticas, e também como recurso para o desenvolvimento de grupos de apoio psicossocial junto a servidores/as que atuam na segurança pública. $\mathrm{O}$ estudo reitera as desigualdades de poder em relação ao gênero que perpassam a sociedade, inclusive dentro do próprio serviço de apoio às mulheres em situação de violência, apontando para a necessidade de se desvencilhar destas concepções para a concretização de um melhor atendimento. Assim, demanda a necessidade de que outros estudos busquem identificar a melhor forma de intervenção para o auxílio desses/as trabalhadores/as e mulheres em situação de violência.

\section{Informações sobre as autoras:}

\section{Tatiana Machiavelli Carmo Souza}

\section{(iD) https://orcid.org/0000-0001-8834-7022}

\section{(9) http://lattes.cnpq.br/3120018580121934}

Professora Associada I no curso de Psicologia da Universidade Federal Catalão (UFCAT). Doutora (2012) e Mestra (2009) em Serviço Social pela Unesp/Franca. Especialista em Psicopedagogia (2007) pela Universidade Castelo Branco. Graduada em Psicologia pela Universidade Federal de Uberlândia (2003). Líder do Grupo de Pesquisas "Teoria histórico-cultural e processos psicossociais" e membro do Grupo de Pesquisas "Dialogus - Estudos Interdisciplinares em Gênero, Cultura e Trabalho", ambos da UFCAT (Diretório dos Grupos de Pesquisa no Brasil, Lattes-CNPq). Membro do GT "A Psicologia sócio-histórica e o contexto brasileiro de desigualdade social" (Anpepp). Avaliadora de cursos de graduação do Instituto Nacional de Estudos e Pesquisas Educacionais Anísio Teixeira. Revisora de periódicos de nível nacional e internacional. Apresenta experiência profissional em Psicologia Social, atuando principalmente nos seguintes temas: gênero e violência contra mulheres, famílias, políticas públicas e subjetividade.

\section{Thaís Ferreira Martins}

\section{iD https://orcid.org/0000-0002-2603-1855}

(9) http://lattes.cnpq.br/8766003242154963

Graduada em Psicologia pela Universidade Federal de Goiás Regional Jataí (2014). Participou de projetos de pesquisa e extensão relacionados à discussão sobre gênero, violência contra a mulher, Delegacia e Juizado Especializados em Atendimento à Mulher de Jataí-GO. Participou de Iniciação Científica em Matemática Aplicada pela OBMEP/CNPq (2009-2010).

\section{Contribuição das autoras:}

As autoras colaboraram ao longo do processo, desde a elaboração até a revisão final do manuscrito. Ambas aprovaram o manuscrito final para publicação.

\section{Como citar este artigo:}

\section{ABNT}

SOUZA, Tatiana Machiavelli Carmo; MARTINS, Thais Ferreira. Vivências de policiais de uma DEAM no Sudoeste Goiano. Fractal: Revista de Psicologia, Niterói, v. 33, n. 1, p. 21-30, jan./abr. 2021. https://doi.org/10.22409/1984-0292/v33i1/5776

\section{APA}

Souza, T. M. C., \& Martins, T. F. (2021, Janeiro/Abril). Vivências de policiais de uma DEAM no Sudoeste Goiano. Fractal: Revista de Psicologia, 33(1), 21-30. doi: https://doi.org/10.22409/19840292/v33i1/5776

\section{Copyright:}

Copyright (C) 2021 Souza, T. M. C., \& Martins, T. F. Este é um artigo em acesso aberto distribuído nos termos da Licença Creative Commons Atribuição que permite o uso irrestrito, a distribuição e reprodução em qualquer meio desde que o artigo original seja devidamente citado.

Copyright (C) 2021 Souza, T. M. C., \& Martins, T. F. This is an Open Access article distributed under the terms of the Creative Commons Attribution License, which permits unrestricted use, distribution, and reproduction in any medium, provided the original article is properly cited.

\section{Referências}

ANDRADE, Fabiana. Fios para trançar, jogos para armar: o fazer policial nos crimes de violência doméstica e familiar contra a mulher. 2012. 218 f. Dissertação (Mestrado em Antropologia Social) - Universidade Estadual de Campinas, Campinas, SP, 2012. Disponível em: http://repositorio.unicamp.br/jspui/ handle/REPOSIP/278986. Acesso em: 30 mar. 2016.

BANDEIRA, Lourdes Maria. Violência de gênero: a construção de um campo teórico e de investigação. Sociedade e Estado, Brasília, v. 29, n. 2, p. 449-469, 2014. http://dx.doi.org/10.1590/ S0102-69922014000200008

BAQUERO, Rute Vivian A. Empoderamento: instrumento de emancipação social? Uma discussão conceitual. Revista Debates, Porto Alegre, v. 6, n. 1, p. 173-187, 2012. https://doi. org/10.22456/1982-5269.26722

BARDIN, Laurence. Análise de conteúdo. Lisboa: Edições 70, 1977.

BRASIL. Presidência da República. Casa Civil. Subchefia para Assuntos Jurídicos. Lei $n^{\circ} 11.340$, de 7 de agosto de 2006. Cria mecanismos para coibir e prevenir a violência doméstica e familiar contra a mulher e dá outras providências. 2006. Disponível em: http://www.planalto.gov.br/ccivil_03/ Ato2004-2006/2006/Lei/L11340.htm. Acesso em: 13 mar. 2015 .

BRASIL. Ministério da Justiça. Norma Técnica de Padronização das Delegacias Especializadas de Atendimento às Mulheres - DEAMs. Edição atualizada. Brasília, 2010. Disponível em: https://assets-compromissoeatitude-ipg.sfo2. digitaloceanspaces.com/2012/08/MJ-2010-Norma-TecnicaPadronizacao-DEAMs.pdf. Acesso em: 13 set. 2019.

CAPELLE, Mônica Carvalho A.; MELO, Marlene Catarina de Oliveira L. Mulheres policiais, relações de poder e de gênero na polícia militar de Minas Gerais. Revista de Administração Mackenzie (Online), São Paulo, v. 11, n. 3, p. 71-99, 2010. https://doi.org/10.1590/S1678-69712010000300006 
CORTEZ, Miriam Beccheri. "Sem açúcar, com afeto": estudo crítico de denúncias de violência contra as mulheres e dos paradoxos da judicialização. 2012. 269 f. Tese (Doutorado em Psicologia) - Universidade Federal do Espírito Santo, Vitória, ES, 2012. Disponível em: http://portais4.ufes.br/posgrad/teses/ tese_3608_.pdf. Acesso em: 29 mar. 2016.

DEEKE, Leila Platt et al. A dinâmica da violência doméstica: uma análise a partir dos discursos da mulher agredida e de seu parceiro. Saúde e sociedade, São Paulo, v. 18, n. 2, p. 248-258, 2009. https://doi.org/10.1590/S0104-12902009000200008

DIAS, Maria Berenice. A lei Maria da Penha na justiça: a efetividade da Lei 11.340/2006 de combate à violência doméstica e familiar contra a mulher. 3. ed. São Paulo: Revista dos Tribunais, 2012.

GOMES, Nadirlene Pereira et al. Violência conjugal: elementos que favorecem o reconhecimento do agravo. Saúde em debate, Rio de Janeiro, v. 36, n. 95, p. 514-522, 2012. http://dx.doi. org/10.1590/S0103-11042012000400003

GUIMARÃES, Maisa Campos; PEDROZA, Regina Lucia Sucupira. Violência contra a mulher: problematizando definições teóricas, filosóficas e jurídicas. Psicologia e Sociedade, Belo Horizonte, v. 27, n. 2, 2015. https://doi org/10.1590/1807-03102015v27n2p256

MIZUNO, Camila; FRAID, Jaqueline Aparecida; CASSAB, Latif Antonia. Por que elas simplesmente não vão embora? In: SIMPÓSIO SOBRE ESTUDOS DE GÊNERO E POLÍTICAS PÚBLICAS, 1, 2010,Londrina. Anais... Londrina: Universidade Estadual de Londrina, 2010. Disponível em: http://www.uel.br/ eventos/gpp/pages/arquivos/3.CamilaMizuno.pdf. Acesso em: 15 mar. 2016

MONTEIRO, Fernanda Santos. O papel do psicólogo no atendimento às vítimas e autores de violência doméstica. 2012 63 f. Monografia (Graduação em psicologia) - Faculdade de Ciências da Educação e Saúde, Centro Universitário de Brasília, Brasília, 2012. Disponível em: https://repositorio.uniceub.br jspui/bitstream/123456789/2593/3/20820746.pdf. Acesso em: 12 fev. 2016.

MORAES, Aparecida Fonseca; RIBEIRO, Letícia. As políticas de combate à violência contra a mulher no Brasil e a "responsabilização" dos homens autores da violência. Sexualidad, Salude Y Sociedad, Rio de Janeiro, n. 11, p. 37-58, 2012. https://doi.org/10.1590/S1984-64872012000500003

NUNES, Patrícia Tonissi Migliato. A violência contra a mulher e o atendimento prestado às vítimas: a perspectiva do policial civil. 2012. 176 f. Dissertação (Mestrado em Educação Especial) - Universidade Federal de São Carlos, São Carlos, 2012. Disponível em: https://repositorio.ufscar.br/handle/ ufscar/3100. Acesso em: 21 jan. 2016.

OBSERVE - Observatório pela aplicação da Lei Maria da Penha. Condições para aplicação da Lei 11.340/2006 (Lei Maria da Penha) nas Delegacias Especializadas de Atendimento à Mulher (DEAMS) e nos Juizados de Violência Doméstica e Familiar nas capitais e no Distrito Federal. Relatório final, nov. 2010. Disponível em: http:/www.observe. ufba.br/_ARQ/Relatorio\%20apresent\%20e\%20DEAMs.pdf. Acesso em: mar. 2016.
PAIXÃO, Leilane Almeida. Violência e sofrimento nas relações intimo-afetivas: possibilidades compreensivas no contexto de uma delegacia da mulher. 2013. 118 f. Dissertação (Mestrado em Psicologia Clínica) - Universidade Católica de Pernambuco, Recife, 2013. Disponível em: http://tede2.unicap. br:8080/handle/tede/193. Acesso em: 22 abr. 2016.

PASINATO, Wânia. Acesso à justiça e violência doméstica e familiar contra as mulheres: as percepções dos operadores jurídicos e os limites para a aplicação da Lei Maria da Penha. Rev. direito GV, São Paulo, v. 11, n. 2, p. 407-428, dez. 2015. https://doi.org/10.1590/1808-2432201518

PIOSIADLO, Laura Christina Macedo; FONSECA, Rosa Maria Godoy S.; GESSNER, Rafaela. Subalternidade de gênero: refletindo sobre a vulnerabilidade para a violência doméstica contra a mulher. Escola Anna Nery, Rio de Janeiro, v. 18. n. 4. p. 728-733, 2014. Disponível em: https://www.scielo.br/scielo. php? script $=$ sci arttext\&pid $=$ S1414-81452014000400728. Acesso em: 23 abr. 2016

PORTO, Madge; BUCHER-MALUSCHKE, Júlia S. N. F. A permanência de mulheres em situações de violência: considerações de psicólogas. Psicologia: teoria e pesquisa, Brasília, v. 30, n. 3, p. 267-276, 2014. https://doi.org/10.1590/ S0102-37722014000300004

SANTIAGO, Rosilene Almeida; COELHO, Maria Thereza Ávila D. O crime passional na perspectiva de infratores presos: um estudo qualitativo. Psicologia em estudo, Maringá, v. 15 , n. 1, p. 87-95, 2010. https://doi.org/10.1590/S141373722010000100010

SCOTT, Joan Wallach. Gênero: uma categoria útil de análise histórica. Educação \& Realidade, Porto Alegre, v. 20, n. 2, p. 71-99, jul./dez. 1995. Disponível em: https://seer.ufrgs.br/ index.php/educacaoerealidade/article/view/71721. Acesso em: 15 ago. 2016.

SILVA, Kelly. As DEAMs, as corporações policiais e a violência contra as mulheres: representações, dilemas e desafios. Revista Brasileira de Segurança Pública, São Paulo, v. 6, n. 1, p. 132154, 2012. Disponível em: http://revista.forumseguranca.org. br/index.php/rbsp/article/view/114. Acesso em: abr. 2016.

SOUZA, Maria Clara Guimarães; SOUZA, Tatiana Machiavelli C. Psicologia e políticas públicas de enfrentamento à violência contra mulheres: experiências de universitárias. Psicologia Revista, São Paulo, v. 28, n. 1, p. 125-149, 2019. https://doi. org/10.23925/2594-3871.2019v28i1p125-149

SOUZA, Tatiana Machiavelli C.; REZENDE, Fernanda Ferreira. Violência contra mulher: concepções e práticas de profissionais de serviços públicos. Estudos Interdisciplinares em Psicologia, Londrina, v. 9, n. 2, p. 21-38, 2018. Disponível em http:// pepsic.bvsalud.org/scielo.php? script=sci arttext\&pid=S223664072018000200003\&lng=pt\&nrm=iso. Acesso em: $10 \mathrm{dez}$. 2019.

SOUZA, Tatiana Machiavelli C.; SABINI, Kelen. Mas o que é o amor? Representações sociais em mulheres em contexto de violência doméstica. Perspectivas em psicologia, Goiás, v. 19, n. 1, p. 162-178, 2015. Disponível em: http://www. seer.ufu.br/index.php/perspectivasempsicologia/article/ view/30542/16627. Acesso em: 10 jun. 2016. 
SOUZA, Tatiana Machiavelli Carmo; SOUSA, Yara Layne Resende. Políticas públicas e violência contra a mulher: a realidade do sudoeste goiano. Rev. SPAGESP, Ribeirão Preto, v. 16, n. 2, p. 59-74, 2015. Disponível em http://pepsic. bvsalud.org/scielo.php?script=sci_arttext\&pid=S167729702015000200006\&lng=pt\&nrm=iso. Acesso em: 12 out. 2019.

SOUZA, Tatiana Machiavelli C.; SANTANA, Flávia Rezende M.; MARTINS, Thaís Ferreira. Violência contra a mulher, Polícia Civil e Políticas Públicas. Pesquisas e Práticas Psicossociais, São João del Rei, v. 13, n. 4, p. 1-13, 2018. Disponível em: http://www.seer.ufsj.edu.br/index.php/revista ppp/article/view/3150. Acesso em: 12 out. 2019. 